\title{
Reactions of general practitioners, district nurses and specialist providers to the development of a community palliative care service
}

Christine Ingleton School of Nursing and Midwifery, University of Sheffield, Sheffield, UK

\begin{abstract}
Hospice care is evolving from the traditional in-patient bedded unit into a system of support which is community focused. The cornerstone of this 'community model' of palliative care rests on successful collaboration with the primary health care team (PHCT). However, there is evidence that establishing a community service is not straightforward, and acceptance in principle is not always translated into practice. This article presents the findings of an evaluation of one such community palliative care service from the perspective of local general practitioners (GPs) and district nurses (DNs). A combination of interview and survey data is presented. A positive picture emerges. The findings suggest that the task of promoting and integrating the service in the community has been successful. The service was seen by members of the PHCT as helping to provide a choice of care settings and helping patients to remain at home. It was not perceived as having caused extra work or complicated lines of communication. However, it is an area which will require constant attention as other factors come into play.
\end{abstract}

Key words: community palliative care; evaluation; multidisciplinary research; needs assessment; primary care; specialist palliative care

\section{Introduction}

The hospice movement began in the 1960s as a radical alternative to traditional cancer care. In its development as a specialty, palliative care currently faces challenges on two fronts as resources move away from high-technology beds towards keeping people at home for as long as possible, and as palliative care providers are urged to extend their services to care for those with nonmalignant terminal illness. The question of the most effective means of providing appropriate care to an expanding population is a subject of current debate. However, perhaps of greater importance is the

Address for correspondence: Dr Christine Ingleton, Lecturer in Nursing, School of Nursing and Midwifery, University of Sheffield, Winter Street, Sheffield S3 7ND, UK. question of the type of care required by the variety of patients who may be served by this expansion of services in a variety of care settings. Hospice care is evolving from the traditional in-patient bedded unit into a system of support which includes some hospice beds but which now crosses the divide between primary care and tertiary care by allowing people to stay at home for as long as possible. The trend towards a more diverse service provision acknowledges that palliative care in not dependent on a building or even on beds (as new community-based services demonstrate), but depends on a patient-centred, holistic, caring approach towards those who are terminally ill (Kurti, 1993). This focus on community care has a number of dimensions. It can be seen as part of a necessary diversification of hospice care into a variety of settings. It entails planned integration into a network of existing provision. It also fits

1463-4236(2000)PC003XX 
more appropriately with a client-centred and needs-led approach to provision, since it allows for flexible delivery of holistic care which may be tailored to individual circumstances. The approach lends itself in turn to a breakdown of the traditional emphasis on terminal care, in favour of continuous care throughout the progression of the disease. Finally, and significantly in the context of spiralling costs of health care, community projects incur a relatively low cost, with the emphasis on service development in the short term rather than fundraising for expensive buildings (Clark and Neale, 1994).

This paper presents the findings of an evaluation of one such community-based palliative care service from the perspective of local GPs, DNs and specialist providers. The paper forms part of a prospective longitudinal case study of the service which began in its pre-operational stage (Clark, 1993) and which continued in a multidisciplinary evaluation of the service commissioned after the service became fully operational (Ingleton, 1997).

\section{Background}

Most research on the views of other health-care professionals with regard to specialist palliative care has focused on the primary health care team (PHCT). Over the past 30 years there have been a number of studies asking PHCTs to assess their propensity to care for terminally ill patients (Wilkes, 1965; Haines and Booroff, 1986; Wakefield et al., 1993; Dworkind et al., 1994; Robbins et al., 1994). In most cases, the results have been positive, reporting high levels of satisfaction with specialist services (Robbins, 1998). However, a number of problems have been identified. Communication difficulties have been highlighted by many studies (Copperman, 1988; Boyd, 1993; Robbins et al., 1996), together with confusion about the respective roles of the specialist and nonspecialist services (Seamark and Thorne, 1993; Robbins et al., 1996). A need for more education and training, especially in relation to symptom control, communications and caring for patients with nonmalignant terminal conditions, is a continuing theme (Boyd, 1993, 1995; Seamark and Thorne, 1993; Robbins, 1998).

Recent legislation, including the The New NHS: Modern, Dependable (Department of Health, 1997) and A Policy Framework for Commissioning Cancer Services (Department of Health, 1995) places strong emphasis on the provision of community services, calling for effective communication between different disciplines within the primary health care team, across the primary/secondary interface and between health-care professionals and patients. This locates the PHCT centrally in the provision of services and makes it pivotal to the shaping and planning of local health services in the future.

Thus asking community nurses and GPs what they think about specialist palliative care services is important for three reasons. First, an important criterion for assessing the effect of any new palliative care service is the extent to which it is successful in gaining the support of the existing PHCT. Secondly, it is an important way of discovering service gaps and problems. Thirdly, it is important to know why members of the PHCT are satisfied or dissatisfied with services.

\section{Study setting}

The study is located in Newark, a market town in the East Midlands of England. The town, together with its surrounding catchment area has a population of approximately 104000 people. A range of services is provided by the PHCTs, which include 35 GPs and 27 DNs. Specialist palliative care is provided by a Macmillan nurse who is based in Newark and an in-patient hospice which is located about 20 miles away and which became operational in 1991. Marie Curie palliative nursing services, chiefly in the form of night-sitting, are also available.

In 1991, Newark and District Hospice Aid (known locally as Beaumond House), which is a palliative care facility, started its information service. By the end of 1995 it was fully operational with three respite beds, day-care, community-care and bereavement-care services, educational provision and a welfare rights service. In developing the service, high priority has been given to forging links with members of the PHCT and other professionals within the locality. Prior to setting up the service a survey of need was undertaken, canvassing the opinion of members of the PHCT. The overall message of the study was plain. A great deal of unmet need was discernible within the local community served by the statutory services and the planned new service (Clark and Neale, 1994), and there was clearly scope for promotion of Newark and District Hospice Aid's activities. Importantly, 
there was substantial agreement about the nature of this need, and the newly-formed service based at Beaumond House was perceived as being in a strong position to meet some of it.

This paper focuses on the extent to which the service has been successful in responding to unmet needs that were identified 5 years earlier.

\section{Aims and methods}

The aims of this aspect of the study were twofold. The first aim was to assess the changes in knowledge about and support for a newly developed and community-based palliative care service from the viewpoint of local GPs and DNs. Secondly, we intended to evaluate how successful GPs and DNs felt the service had been in integrating with existing services and meeting perceived local needs.

The evaluation was conducted by a multidisciplinary team and was guided by the methodological principles of formative, qualitative evaluation (Ingleton et al., 1997, 1998). The study was therefore conducted along participatory lines whereby the overall aims and methodology reflected the interests and concerns of the service providers as well as the evaluation team. This model of evaluation utilizes both quantitative and qualitative approaches to data collection and draws upon a variety of sources. For this aspect of the evaluation the main method of soliciting the views of members of the PHCT was a questionnaire survey, which was sent to all GPs and DNs in the service catchment area. The questionnaire, which collected both quantitative and qualitative data, was a modified version of that used in other studies but it also incorporated questions designed to replicate those asked in the earlier survey (see Appendix 1). In total, 27 GPs $(75 \%)$ and 14 DNs $(56 \%)$ responded following the distribution of a reminder letter. Semi-structured interviews using an aide-mémoire were also conducted with members of staff of Beaumond House and with local palliative care specialist providers, in order to elicit their perspective on the development of the service. In addition, the main researcher (C.I.) spent 2 days per week at Beaumond over a 6-month period. This provided the opportunity to analyse documents such as minutes of meetings, teaching programmes and job descriptions. It also provided this researcher with the opportunity to talk informally with staff and to take lunch and tea breaks with them.

\section{Findings}

The findings elicited by the questionnaire survey are presented alongside the qualitative data obtained from interviews and observation.

\section{Integrating into the service}

The importance of good working relationships with the PHCTs has been recognized by the Beaumond House staff, and steps have been taken to develop these relationships. Members of the Beaumond House staff reflected on the 'early days' when suspicions about the proposed service were evident:

You know it wasn't easy to go out there. Sometimes it was like going into a lion's den. It didn't exactly make you feel good. It would have been easy to retreat into your shell ... I think they thought we were trespassing. I mean you think I don't need this. Then I remembered we kept going because we believed in it (Beaumond House).

It was hard, harder for some than others. . . . I lost heart a few times, I think we all did. xxxx kept us going. It worked in the end. They have accepted us I think ... you will be able to tell us if I am right or not.

The above excerpts illustrate some of the difficulties that new services face in gaining credibility and legitimacy in the eyes of established services. Although the establishment of the service at Beaumond House was not intended to supersede existing provision, it did by definition suggest some inadequacies within it.

A belief in the philosophy underpinning the planned service galvanized members of the team into action at a time when rewards were sparse and difficult to define. It was felt that the community care manager, through her enthusiasm, played an important part in rekindling a flagging team spirit and was instrumental in uniting the group in a common sense of purpose.

\section{Referral to the service and understanding of the aims of the service}

The survey results showed that all 27 GPs and 10 out of 14 DNs had referred patients to the service. Those DNs who had not referred a patient indicated that this was because of their junior 
position rather than being due to any desire not to refer. In total, 26 out of 27 GPs and 13 of 14 DNs felt that the aims of the service were relevant to local need and that they were being achieved. No difficulties had been experienced by either GPs or DNs in referring patients to Beaumond House. Both GPs and DNs had a comprehensive understanding of the referral criteria although, surprisingly for a service which had been conceived as community focused, more emphasis was placed on respite services than on community care. A number of positive comments were offered:

No difficulties, always helpful and willing to take referrals. (DN No. 8)

They are very helpful and try very hard to provide needed input of care. (DN No. 4)

Only two GPs had experienced difficulties, both of which concerned the initial lack of weekend cover, and they acknowledged that this problem had now been resolved.

A total of 11 GPs cited a diagnosis and terminal care as the main criterion for admission to Beaumond House (see Figure 1). The original aim of the service was to provide a community-based service and not a house-based terminal care provision. This supports the contention that even when community care is the prime objective, as in the case described here, there are factors which constrain its execution, the most potent of these being attitudes, values and demands that exist in the local community (which include professional as well as lay perceptions). Despite policy developments and publicity efforts by Beaumond House GPs and, to

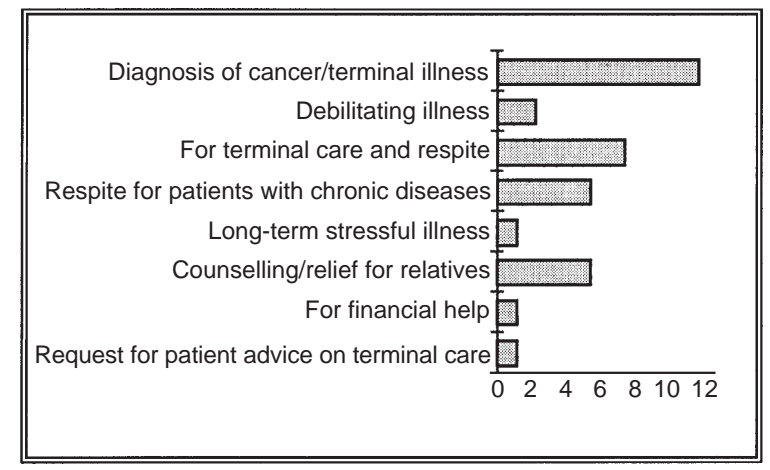

Figure 1 Criteria for admission as defined by GPs ( $n=$ 27). a lesser extent, DNs (see Figure 2), perceptions of the service were based on a conception of hospice care as a house-based terminal care facility rather than as a community-based service, thus supporting the notion that community effort still tends to be mobilized around the tangible goal of a care setting rather than the provision of a service, which may be relatively invisible (Clark and Neale, 1994).

Examples of this perception of the service as providing 'house-based' terminal care include the lack of knowledge of services directly and indirectly related to carers, such as the homesitting service, which is especially valuable to carers who need a break from their caring responsibilities, yet GPs were unaware of the service. This may reflect GPs prioritizing the patient's needs over those of the carer, and may be due to a tendency to view informal carers as mere extensions of the patient rather than as clients in their own right (Seale, 1991), with the result that the needs of carers become submerged and thus largely ignored.

The GPs and DNs were asked what they thought were the aims of Beaumond House. The majority of GPs cited care and support for terminally ill patients and their carers as being the main aim $(n=23)$. It is noteworthy that only three GPs saw the aim of Beaumond House as being the provision of community help. The original intention of Beaumond House was to provide a community-based service. However, over the course of the service's development this seems to have been translated into a more house-based approach to care provision, which appears to be reflected in the GPs' perceptions of the aims of Beaumond House. Only two DNs cited care for terminally ill patients as

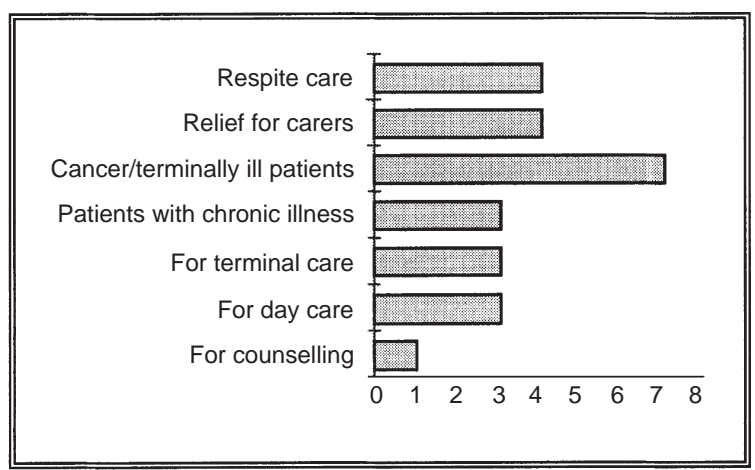

Figure 2 Criteria for admission as defined by district nurses $(n=14)$.

Primary Health Care Research and Development 2000; 1: 15-27 
being the aim of Beaumond House. The most common theme was that of support for carers $(n=7)$, followed by holistic palliative care $(n=6)$, both of which are important aims of the service. The aims as stated by the DNs may reflect their more socially orientated approach to patient care:

It is providing a valuable flexible service which was much needed in the community. (GP No. 25)

I think Beaumond House has achieved what it set out to do, deliver a good quality service for a vulnerable group. They have our full support. (DN No. 4)

\section{Satisfaction with service provision}

The GPs and DNs were then asked to rate the services provided by Beaumond House (see Figure 3), and 26 of the 27 GPs and all 14 DNs completed this section.

The most highly rated service was that provided by the Macmillan nurse, followed by the day-care and respite services. It is possible that these were rated higher than the other services because they were more familiar to the respondents, and there- fore they have a clearer picture of what the services provide and how good they are.

Relationships with the local Macmillan nursing service have been given careful attention at Beaumond House. Discussing the establishment and funding of Macmillan nurses, Taylor (1983) points out that:

The service depends for its effectiveness on the willingness of other professionals to accept the advice and expertise which it proffers. ... The setting up of specialist services is not always welcomed, initially at least, by doctors and nurses, who may not wish to share responsibility for the care of their patients and may be sensitive to the interference of outsiders on their 'patch'. (Taylor 1983:29)

The locality's Macmillan nurse was based at Beaumond House and was a member of a fourperson team employed by the Trust. She was a highly visible member of the team, and her specialist knowledge combined with her diplomatic approach made for an effective working relationship both within the 'house' and in the community.

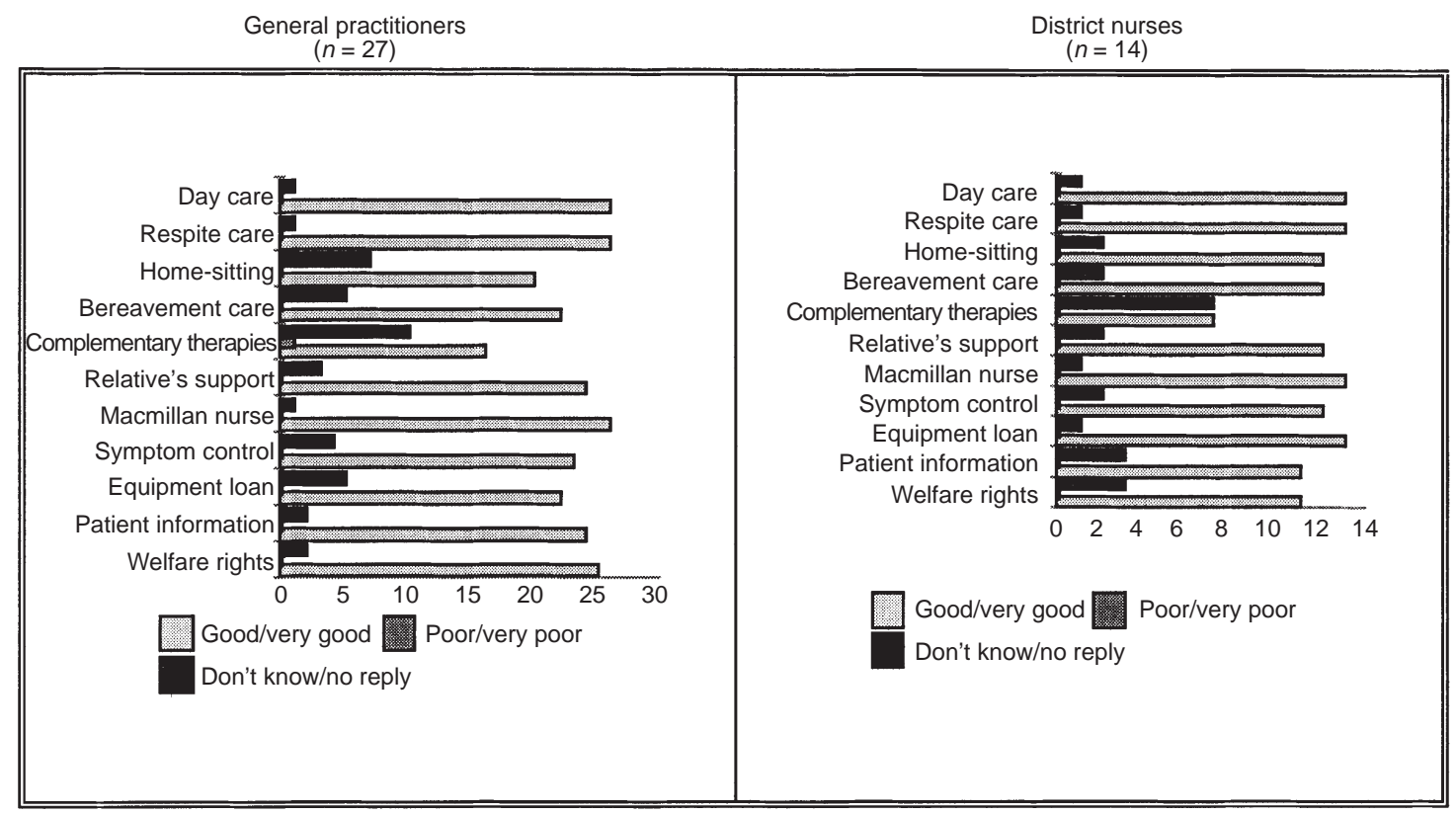

Figure 3 Quality of services provided by Beaumond House. 
Furthermore, she appeared to act as a 'structural facilitator' between the local in-patient care unit and Beaumond House. Her close proximity meant that staff (and patients) at Beaumond House gained increased access to her skills and expertise. Her presence at both the in-patient unit and Beaumond House was undoubtedly an influential mediating factor, and was perceived by some as a bridge that could span the 'different models' of care in a context where relationships on each side have been shrouded by a degree of mutual suspicion. As she explained:

I like to think it [the arrangement] works well for both sides. Sometimes I feel a bit like piggy in the middle, but it is not a great problem. I think I have the best of both worlds. The two places are different, each with their different problems. I feel I can see things from both sides and I think for that reason I can say 'eh look at it from the other side'.

From the outset, then, this arrangement has worked well from the perspective of both staff at Beaumond House and the Macmillan nurse herself. Both sides have succeeded in working effectively together while maintaining their respective evolving roles. None of the problems experienced by similar organizations elsewhere, such as concerns over duplication of work, and 'encroachment', were detectable (see, for example, Neale, 1992). Concerted efforts were made both by managers at Beaumond House and by the Macmillan nurse to work closely together in order to avoid duplication and provide an integrated service for patients and carers. The different skills and managerial styles were described as complementary by a number of staff. The community care manager explained:

I think X [Macmillan nurse] has very different skills both in terms of her expertise in palliative care issues and in her approach to issues ... she is sensitive to moods and things. I have other experience from my different background ... not so much experience in palliative care as such, but I don't think that is a problem, we play to each other's strengths.

The explanation for the success of this arrangement appears to lie in a willingness of both sides to share expertise in a milieu of openness and trust. Carrying out joint assessments, attending fundrais- ing events, attendance at all staff meetings and shared teaching sessions were tangible demonstrations of the extent to which the Macmillan nurse appeared to be accepted and indeed welcomed as a member of the team.

Featured as a 'member of the Beaumond House team' in publicity material, this total integration of the Macmillan service into the team did, however, cause potential difficulties, as a member of staff from the in-patient hospice explained:

I am pleased with the way $\mathrm{X}$ [Macmillan nurse] is integrated into the team there, it is a great success, but on the brochure it looks like she is employed by them [Beaumond House], no acknowledgment is given to the fact she works for this Trust.

It may be viewed as paradoxical that, whereas in the past the practice of involving the Macmillan service in new community ventures was crucial, there now exists a concern that they may 'become too integrated' and lose their identity.

The GPs and DNs were asked to consider a series of attitude statements, the results of which indicated a high level of satisfaction with the services provided by Beaumond House. All but one GP and one DN felt that Beaumond House Aid was important to the provision of palliative care in their area. The services were also regarded as having a positive effect on local care, without inconveniencing the GPs or DNs by causing more work or complicating lines of communication (see Figure 4).

\section{Education and training}

In the 1991 survey, GPs and DN had requested information/education in pain relief, symptom control and counselling skills. By 1996, a large proportion of GPs and DNs had received education/ information from Beaumond House staff. Information and skills had also been passed on to the GPs and DNs, but not formally and not to the same extent. The training received at the time of the study is summarized in Table 1.

It appears that the DNs had greater access to the information provided by Beaumond House. In some cases, twice as many DNs as GPs had received information or education in the subject area.

Ongoing informal feedback was given to GPs, and the monthly meetings which are held between DNs and staff at Beaumond House had served to 

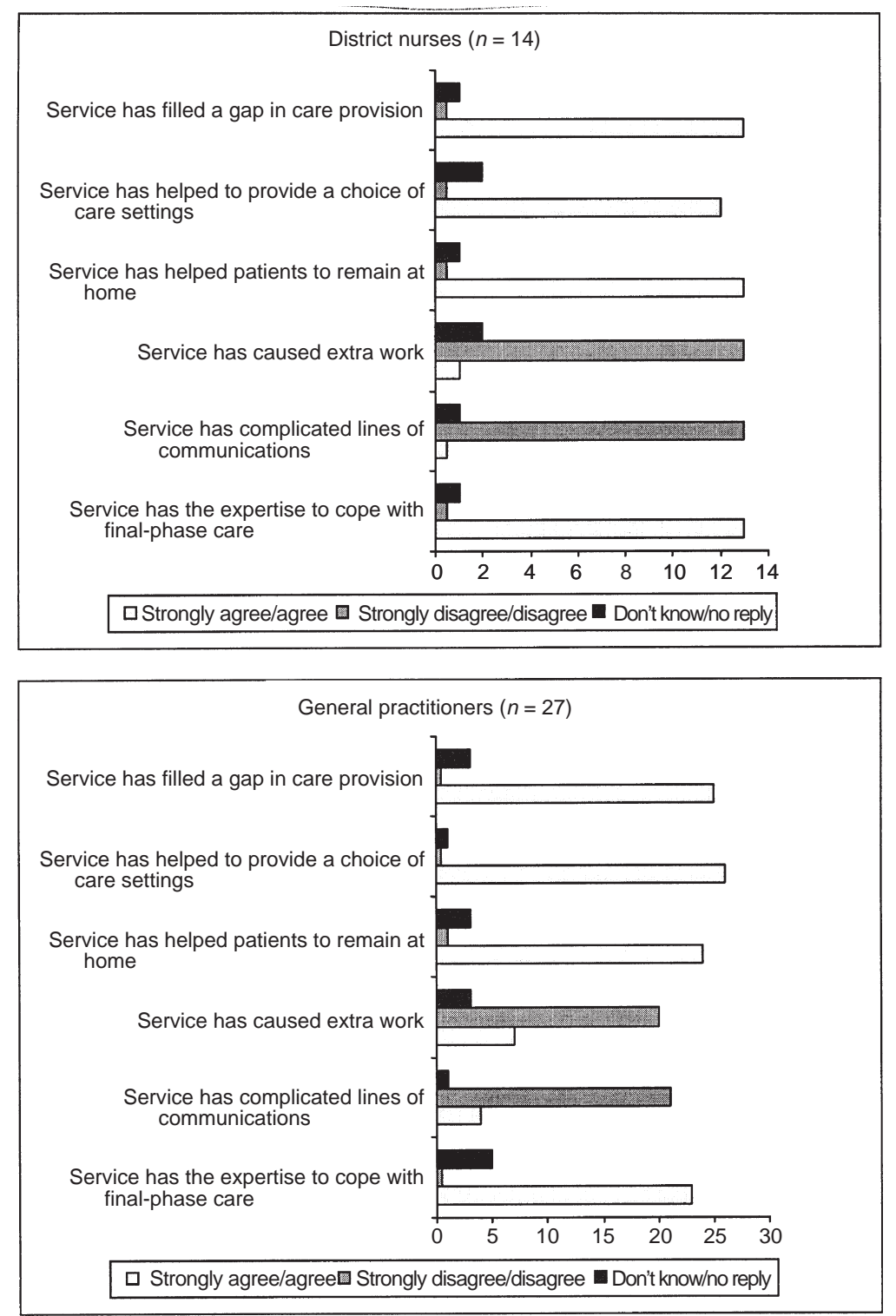

Figure 4 Attitude to services provided by Beaumond House.

foster good working relationships. GPs and DNs were regular visitors to Beaumond House, not only in their 'official' capacity at pre-arranged times in order to visit patients, but also as colleagues who needed no invitation to 'drop in'.

The only (constructive) criticism related to the need to have regular updates on what equipment and residential care were available.
Beaumond House provides a service which is invaluable to our service. (DN No. 7)

I am highly impressed with the services that Beaumond House provides for patients, carers and relatives and it is of great value to the DN service. (DN No. 2)

We are very pleased to have the help and 
Table 1 Training received by Beaumond House at the time of the study

\begin{tabular}{lrr}
\hline Skill area & $\begin{array}{l}\text { GPs } \\
(n=27)\end{array}$ & $\begin{array}{l}\text { District nurses } \\
(n=14)\end{array}$ \\
\hline Symptom control & $12(44 \%)$ & $9(64 \%)$ \\
Pain relief & $10(37 \%)$ & $10(71 \%)$ \\
Counselling skills & $6(22 \%)$ & $6(43 \%)$ \\
Communication skills & $5(19 \%)$ & $5(36 \%)$ \\
Bereavement counselling & $7(26 \%)$ & $7(50 \%)$ \\
\hline
\end{tabular}

support of Beaumond House. They are an excellent team and provide an essential service. In fact we would have difficulty managing without them. (DN No. 1)

An excellent service which should be expanded. (GP No. 2)

Very happy so far, kind supportive staff, thank you. (GP No. 6)

What did we do without it? Excellent service with pleasant professional attitude, supporting the PHCT, provides enhanced palliative care in the community. (GP No. 3)

These quotes appear to be typical of the way in which the GPs and DNs viewed the Beaumond House staff and services.

\section{Discussion}

The need for a local specialist palliative care service was recognized in 1991 and, as a response, Beaumond House, in collaboration with community health professionals, has worked to meet this need.

However, new community services can face the potential problem of finding a 'market niche' (Clark and Neale, 1994) which complements and augments rather than supplants existing provision. There is evidence that establishing a community service is less than straightforward and acceptance and support in principle are not always translated into practice (Carstens, 1986; Neale 1993). Potential hostility to the idea of specialist provision for palliative care may stem from a wish to retain control of patients in their care. This did not appear to be the case in this study. Here GPs and DNs present a positive picture of the service, and this seems to have been achieved to a large extent by willingness to share ideas and expertise, coupled with sustained effort by Beaumond House staff 'to go out' and promote a community service among a group of nonspecialist providers who had expressed initial scepticism about the planned service. Importantly, the role of the primary health care team was taken into account in order to avoid duplication of effort and to establish clear lines of accountability for the welfare of the patient.

However, it is worth looking critically at some of the possible underlying reasons for such a positive response. Four points are salient here. First, as death has become more institutionalized over the past 40 years, nonspecialist providers may not have the same degree of experience of dealing with terminally ill patients and their carers that they once had (Doyle, 1980). It is estimated that GPs care for less than six terminally ill patients a year, and doctors can lose skills and confidence in dealing with people who are dying (Haines and Booroff, 1986). Thus they may not be the best placed group of professionals to make judgements about the appropriateness or quality of a service for this particular client group.

The second inter-related point reinforces the first. Pragmatically, GPs and DNs may be relieved of the burden of responsibility of care for very ill patients by referral to another agency. Generally, most members of primary health care teams have had little specialist training, and may have yet to grasp the hospice ideals of open communication, informed choice and intensive emotional support for both patient and carer (Addington-Hall et al., 1991; Seale, 1992). The challenging nature of caring for a terminally ill patient and their family, in terms of providing both physical care but perhaps more notably psychosocial care, in a context of 
'open awareness' where a terminal prognosis may be known, may have prompted a more positive response among the nonspecialist providers to the service provided by Beaumond House.

Thirdly, under present funding arrangements GPs receive services for terminally ill patients without cost. In short, there could be an element of 'it is the best we can get and free'.

Fourthly, separating the effects of inadequate or insufficient mainstream provision from the satisfaction felt with specialist services because they 'fill a gap', rather than because of their particular contribution to patient care, is problematic. It is for this reason that it is important to know why GPs and community-based staff were satisfied with the specialist services.

That said, the empirical data support the view that Beaumond House was seen by GPs and DNs as having helped to provide a choice of care settings, it was viewed as helping patients to remain at home, and it has not been perceived to have caused them extra work or to have complicated lines of communication.

On the basis of the evidence presented above, the task of promoting and integrating the service in the community has been successful. However, it is an area which will require constant nurturing and continued attention as the service expands. It could be argued that there is now a greater choice of care available to the patients and their carers at virtually no extra cost to GPs. The annual cost to the NHS is low. Just over 13\% of the local health authorities' budget for specialist palliative care is spent on these services, with the low costs stemming from Beaumond House's successful fundraising within the community, coupled with the use of unpaid voluntary labour (Ingleton, 1997).

The relationship between new community ventures and other care workers illustrates some of the negotiating and trust-building that has to take place for newcomers to integrate their work within an established network of providers, in a context where both are concerned to establish their own 'territorial boundaries'. However, once this has been achieved, other factors come into play. In addition to professional rivalries, other fundamental organizational problems may surface, and are linked to operational problems in dealing with managers, organizations and hierarchies (in this case from other specialist providers).

In addition, during the course of this study the policy context has changed, and this may hold further challenges for the commissioning of palliative care services. The 1997 White Paper has signaled major changes in GPs' roles in commissioning. In general, palliative care is ranked as a high priority, and such services are therefore likely to be early candidates for commissioning (Barclay et al., 1999). Within the new strategy for commissioning services, various forms of GP purchasing are to be replaced by primary care groups (PCGs), in which both GPs and DNs are to be involved in commissioning services. This could prove to be less than straightforward. For example, in a study by Barclay et al. (1999) which sought to ascertain the views of GPs and DNs concerning their priorities for the future planning of local palliative care services, it was revealed that views of service adequacy and priorities for future development differed significantly between the two professional groups. Resolution of these differences will need to be achieved within these PCGs in the future.

\section{Acknowledgements}

I would like to thank Professor David Clark, University of Sheffield, for supervising this study, and Fiona White, who assisted with data collection. The study was commissioned and funded by North Nottinghamshire Health Authority. The palliative care service has given its permission to be named in publications and the local ethics committee was informed of the study.

\section{References}

Addington-Hall, J.M., MacDonald, L.D., Anderson, H.R. and Freeling, P. 1991: Dying from cancer: the views of bereaved family and friends about their experiences of terminally ill patients. Palliative Medicine 5, 207-14.

Barclay, S., Todd, C., McCabe, J. and Hunt, T. 1999: Primary care group commissioning of services: the differing priorities of GPs and DNs for palliative care services. British Journal of General Practice 49, 181-86.

Boyd, K.J. 1993: Palliative care in the community: views of general practitioners and district nurses in East London. Journal of Palliative Care 9, 33-37.

Boyd, K.J. 1995: The role of specialist home care teams: views of general practitioners in South London. Palliative Medicine 9, 138-44. 
Carstens, J. 1986: A terminal care programme for a rural area. In Turnbull, R., editor, Terminal care. London: Hemisphere, 87-143.

Clark, D. 1993: Partners in care? Hospices and health authorities. Occasional Papers in Social Administration. Aldershot: Avebury.

Clark, D. and Neale, B. 1994: Independent hospice care in the community: two case studies. Health and Social Care 2, 203-12.

Copperman, H. 1988: Domiciliary hospice care: a survey of general practitioners. Journal of the Royal College of General Practitioners 38, 411-13.

Department of Health 1995: A policy framework for commissioning cancer services. A report by the Expert Advisory Group on Cancer to the Chief Medical Officers of England and Wales. London and Cardiff: Department of Health and Welsh Office.

Department of Health 1997: The new NHS: modern, dependable. London: The Stationery Office.

Doyle, D. 1980: Domiciliary terminal care. Practitioner 224, 575-82.

Dworkind, M., Schvartzman, P., Adler, P.S. and Franco, E.D. 1994: Urban family physicians and the care of cancer patients. Canadian Family Physician 40, 47-50.

Haines, A. and Booroff, A. 1986: Terminal care at home: perspective from general practice. British Medical Journal 292, 1051-53.

Hockey, J. 1991: St Columba's Hospice Home Care Service: an evaluation study. Palliative Medicine 5, 315-22.

Ingleton, C. 1997: Evaluating palliative care services: an analysis of two hospices in one health district using a pluralistic case study approach. Unpublished $\mathrm{PhD}$ thesis, University of Sheffield, Sheffield.

Ingleton, C., Field, D. and Clark, D. 1997: Multi-disciplinary case study as an approach to the evaluation of palliative care services: two examples. International Journal of Palliative Nursing 3, 335-39.
Ingleton, C., Field, D. and Clark, D. 1998: Formative evaluation and its relevance to palliative care. Palliative Medicine 13, 187-201.

Kurti, L. 1993: Palliative care in non-malignant disease: the carer's perspective. Unpublished MPhil Thesis, University of Nottingham, Nottingham.

Neale, B. 1992: Palliative care in the community: the development of a rural hospice service in High Peak, North Derbyshire 1988-1992. Occasional Paper No. 5. Sheffield: Trent Palliative Care Centre.

Neale, B. 1993: Informal palliative care in Newark: needs and services. Occasional Paper No.9. Sheffield: Trent Palliative Care Centre.

Robbins, M. 1998: Evaluating palliative care: establishing the evidence base. Oxford: Oxford University Press.

Robbins, M., Jackson, P. and Prentice, A. 1994: Palliative care provision in the South West. Bristol: Health Care Evaluation Unit, University of Bristol.

Robbins, M., Jackson, P. and Prentice, A. 1996: Statutory and voluntary sector palliative care in the community setting: NHS professionals' perceptions of the interface. European Journal of Cancer Care 5, 96-102.

Seale, C. 1991: Death from cancer and death from other causes: the relevance of the hospice approach. Palliative Medicine 5, $13-20$.

Seale, C. 1992: Community nurses and the care of the dying. Social Science and Medicine 34, 375-83.

Seamark, D.A. and Thorne, C.P. 1993: Knowledge and perception of a domiciliary hospice service among general practitioners and community nurses. British Journal of General Practice 43, 57-59.

Taylor, H. 1983: The hospice movement in Britain: its role and its future. London: Centre for Policy on Ageing.

Wakefield, M.A., Beilby, J. and Ashby, M.A. 1993: General practitioners and palliative care. Palliative Medicine 7, 117-26.

Wilkes, E. 1965: Terminal cancer at home. Lancet i, 799-801. 


\section{Appendix 1 Beaumond House Evaluation}

1 Are you aware of the services provided by Beaumond House?

Yes $\square$

2 Have you referred any of your patients to Beaumond House during the last year?

Yes $\square \quad$ No

2a If no, please would you give a reason:

$2 \mathrm{~b}$ If yes, have you experienced any particular difficulties in referring patients to Beaumond House?

3 Do you feel you have enough information to know which patients it would be appropriate to refer to the service?

Yes $\square \quad$ No

3a What is your understanding of the criteria for referring patients to the service?

4 How would you rate the following services provided by Beaumond House?

Day care

Respite care

Home-sitting

Bereavement care

Complementary therapies

Relatives' support

Macmillan nurse

Symptom control

Equipment loan

Patient information

Welfare rights

$\begin{aligned} & \text { Very Good Poor } \begin{array}{l}\text { Very } \\ \text { good }\end{array} \\ & \text { poor know }\end{aligned}$

5 What do you understand to be the aims of Beaumond House?

6 Do you consider the aims to be relevant to local needs?

Yes $\square \quad$ No $\square$

7 Do you feel Beaumond House is achieving its aims?

Yes $\square \quad$ No

Primary Health Care Research and Development 2000; 1: 15-27 
7a For what reasons do you feel Beaumond House is/is not achieving its aims?

8 How important is the contribution of Beaumond House to the provision of palliative care in your area?

$\begin{array}{cccc}\text { Very } & \text { Important } & \begin{array}{l}\text { Don't } \\ \text { know }\end{array} & \begin{array}{l}\text { Not very } \\ \text { important }\end{array}\end{array}$

Thinking about specific aspects of the service provided by Beaumond House, please tick the box which most closely matches your response.

9 The service has filled an important gap in care provision.
Strongly
agree
Agree
Don't
know
Disagree
Strongly
disagree

10 The service has helped to provide a choice of care settings.
Strongly agree
Agree
Don't
know
Disagree
Strongly
disagree

11 The service has helped patients to remain at home when they wanted to.
Strongly
agree
Agree
Don't
Disagree
Strongly
disagree

12 The service has caused extra work for GPs/District Nurses.
Strongly agree
Agree
Don't
know
Disagree
Strongly
disagree

13 The service has complicated lines of communication.
Strongly
Agree
Don't
know
Disagree
Strongly
disagree

14 Beaumond House has the expertise to cope with patients in the final phase of their illness.

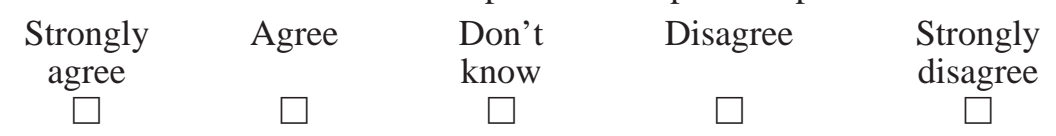

15 Has Beaumond House:

provided you with if not, would you like information/education provision to be made? on any of the following?

Symptom control

Pain relief

Counselling skills

Communication skills

Bereavement counselling

Other (please state) 
Please add any comments you would like to make about the service. 